\title{
Laboratory estimation of the effects of increasing temperatures on the duration of gonotrophic cycle of Anopheles albimanus (Diptera: Culicidae)
}

\author{
Guillermo L Rúa/ , Martha L Q uiñones, Iván D Vélez, Juan S Zuluaga*, William Rojas*, \\ Germán Poveda**, Daniel Ruiz**
}

Programa de Estudio y Control de Enfermedades Tropicales, Facultad de Medicina, Universidad de Antioquia, Medellín, Colombia *Corporación para Investigaciones Biológicas, Medellín, Colombia **Escuela de Geociencias y Medio Ambiente, Universidad Nacional de Colombia, Medellín, Colombia

The increase of malaria transmission in the Pacific Coast of Colombia during the occurrence of El Niño warm event has been found not to be linked to increases in the density of the vector Anopheles albimanus, but to other temperature-sensitive variables such as longevity, duration of the gonotrophic cycle or the sporogonic period of Plasmodium. The present study estimated the effects of temperature on duration of the gonotrophic cycle and on maturation of the ovaries of An. albimanus. Blood fed adult mosquitoes were exposed to temperatures of 24, 27, and $30^{\circ} \mathrm{C}$, held individually in oviposition cages and assessed at $12 \mathrm{~h}$ intervals. At 24,27 , and $30^{\circ} \mathrm{C}$ the mean development time of the oocytes was $91.2 \mathrm{~h}$ (95\% C.I.: 86.5-96), $66.2 \mathrm{~h}$ (61.5-70.8), and 73.1 h(64-82.3), respectively. The mean duration of the gonotrophic cycle for these three temperatures was $88.4 \mathrm{~h}$ (81.88-94.9), $75 \mathrm{~h}$ (71.4-78.7), and $69.1 \mathrm{~h}$ (64.6-73.6) respectively. These findings indicate that both parameters in An. albimanus are reduced when temperatures rose from 24 to $30^{\circ} \mathrm{C}$, in a nonlinear manner. According to these results the increase in malaria transmission during El Niño in Colombia could be associated with a shortening of the gonotrophic cycle in malaria vectors, which could enhance the frequency of man-vector contact, affecting the incidence of the disease.

Key words: gonotrophic cycle - Anopheles albimanus - temperature - El Niño - climate - Colombia

Climate variability is one of many factors that affect the incidence of vector-borne diseases. The El Niño/ Southern Oscillation (ENSO) phenomenon is the most important regulator of climate on interannual timescales in tropical and subtropical regions (Diaz \& Markgraff 2000). ENSO is a natural event produced as a result of the interaction between the ocean and the atmosphere in the equatorial Pacific Ocean. Colombia experiences deficits of rain as well as increasing temperatures during the warm phase of ENSO (El Niño) and the opposite during the cold phase (La Niña). The incidence of malaria in Colombia increases during El Niño events and this has been associated with increments of $2-4^{\circ} \mathrm{C}$ in average air temperature (Poveda \& Rojas 1997, Bouma et al. 1997, Poveda et al. $2000,2001)$. Such rises are known to affect the entomological variables of disease transmission (Macdonald 1957, Detinova 1962, Lindsay \& Birley 1996, Martens 1997).

The evidence indicates that increases in malaria incidence do not necessarily correspond to increased vector density (Bown et al. 1991, PAHO 1996, Rúa et al. 2003), while reductions in other variables such as gonotrophic

Financial support: Comité para el Desarrollo de la Investigación Universidad de Antioquia, COLCIENCIAS (grant 22130412671), Inter-American Institute for Global Change Research

${ }^{+}$Corresponding author. E-mail: g1_rua@guajiros.udea.edu.co Received 16 February 2005

Accepted 5 August 2005 cycles and the extrinsic incubation period of the parasite are generally related to increased incidence of the disease (Macdonald 1957, Detinova 1962, Bruce-Chwatt 1980, Molineaux 1988). These two entomological variables are especially sensitive to changes in environmental temperature (Lindsay \& Birley 1996, Martens 1997, Martens et al. 1999), being reduced with increments in temperature. The kinetics of mosquito oocyte development, maturation of the ovaries, and duration of the gonotrophic cycle, all of them influence the human-vector contact frequency. A reduction in the duration of the gonotrophic cycle would make the vectors bite more often, generating an increased probability of malaria transmission. Although, it is necessary to take into account the reduction in longevity with increments in temperature. A balance between all these variables would explain the effect of climate on malaria transmission.

In this study the effects of temperature on development time of the oocyte and duration of the gonotrophic cycle were studied in An. albimanus, the principal vector of malaria on the Colombian Pacific Coast (Quiñones et al. 1987), under controlled laboratory conditions. These observations are discussed in relation to their implications for malaria transmission in malaria-prone regions of $\mathrm{Co}-$ lombia during El Niño events.

\section{MATERIALS AND METHODS}

Maintenance of mosquitoes - The Cartagena strain of An. albimanus was used to determine the duration of the gonotrophic cycle and oocyte development time. These mosquitoes are adapted to laboratory conditions and matings are easily obtained, resulting in several oviposi- 
tions per generation (Carrillo et al. 1981). The WTB Binder KBF 720 chamber climate used to carry out the experiments was maintained at both constant temperature and relative humidity within limits of $\pm 0.5^{\circ} \mathrm{C}$ and $\pm 5 \% \mathrm{RH}$, respectively. The three temperatures evaluated were 24 , 27 , and $30^{\circ} \mathrm{C}$. Relative humidity and photoperiod were held constant throughout the experiment at $90 \%$ and $12: 12 \mathrm{~h}$, respectively. Duration of the gonotrophic cycle and oocyte development time were estimated from the second oviposition, since the former parameter is highly variable in nulliparous females of An. albimanus. It has been suggested that they require more than one blood meal to complete the first gonotrophic cycle (Briegel \& Hörler 1993).

Adult mosquitoes were obtained by placing pupae inside a 28 x 28 x $29.5 \mathrm{~cm}$ holding cage. Adult mosquitoes were fed ad libitum with a $10 \%$ (w/v) glucose solution since emergence. Fresh glucose solution was provided on the second and fourth days. The newly emerged female mosquitoes were allowed to feed to repletion on the blood of mice (Mus musculus) for $30 \mathrm{~min}$ on the first day. This was repeated during the second and third days. Up to the first oviposition, mosquitoes were maintained at $27^{\circ} \mathrm{C}$.

Oviposition methodology - On day four after adult emergence, all engorged females were removed from the cage with a mouth aspirator and individually placed in oviposition cages consisting of a $9.2 \mathrm{~cm}$-high plastic cylinder of diameter $5.4 \mathrm{~cm}$, capped with nylon mesh and with a circle of paper filter on top of moistened cotton in the base as a substrate to encourage oviposition. Once the mosquitoes laid eggs, they were placed individually in new oviposition cages, where they fed only once (to repletion) on the blood of one of the authors (GR), who placed his fingers on the mesh of the cage. After feeding, the oviposition cages were placed inside the climate chamber at one of the selected temperatures. Similarly to the first oviposition, mosquitoes that did not feed were eliminated from the study.

Oocyte development - Development of the oocytes was evaluated every $12 \mathrm{~h}$ from the moment of blood feeding. A total of 308 mosquitoes was observed and dissected to estimate the variation in the duration of oocyte development of An. albimanus at different temperatures. Monitoring of oocyte development was carried out for five days, which is known to be sufficient time, in An. albimanus, for the second oviposition to occur (Rodríguez et al. 1992). The degree of oocyte maturation was established by observing the abdominal appearance and the blood digestion process (Sella stages) and by dissection and identification of the ovarian stages as described by Christophers (Christophers 1911, WHO 1975), in which pairs of ovaries were placed on a slide coverslip and their development determined in lots of 20 ovarioles per ovary.

Duration of the gonotrophic cycle - Duration of the gonotrophic cycle corresponds to the period between blood feeding and oviposition (when first eggs were laid). The appearance of eggs in the individual oviposition cages was monitored every $12 \mathrm{~h}$. A total of 93 individual mosquitoes were assessed. Observations of oviposition began when Christophers' stage IV or Sella stage SG (semi-gravid females) were attained, based respectively, on dissections or on the abdominal appearance. The oviposition sites were moistened with water every day to facilitate egglaying.

Circadian rhythm of egglaying - To determine whether the time of blood feeding affected the duration of the gonotrophic cycle, the mosquitoes were fed either in the evening (18:00-19:00) or in the morning (7:00-10:00) and the period during which oviposition occurred was recorded for each group.

Statistical analysis - Kruskal-Wallis statistical tests were carried out to determine whether duration of the gonotrophic cycle was affected by temperature. Chisquared tests were used to establish whether there were differences among the feeding and oviposition times.

\section{RESULTS}

Oocyte development - Time required for ovarian development was inversely proportional to temperature. At $30^{\circ} \mathrm{C}$ the first individuals reached the final stage of oocyte development $24-36 \mathrm{~h}$ after feeding, characterized by the presence of completely formed floats (Christophers' stage V), while at 27 and $24^{\circ} \mathrm{C}$ the first individuals in Christophers' stage V were observed at 36-48 and 48-60 h, respectively.

Oocyte maturation in An. albimanus was not a synchronous process. For example in $84-96 \mathrm{~h}$ post feeding at $24^{\circ} \mathrm{C}$, individuals with oocytes in Christophers' stage V as well as III and IV were found. Similarly, at $27^{\circ} \mathrm{C}$, individuals with oocytes in stage II and III were still observed after $108-120 \mathrm{~h}$ post feeding.

A significant difference was observed in the mean duration of oocyte development based on Christophers' stages with respect to temperature, oocytes taking longer to develop at $24^{\circ} \mathrm{C}$ than at 27 or $30^{\circ} \mathrm{C}$ (Fig. 1). According to the mean development time, Christopher's stage $\mathrm{V}$ was reached after 66.2 and $73.1 \mathrm{~h}$ at 27 and $30^{\circ} \mathrm{C}$ respectively, compared to 91.2 at $24^{\circ} \mathrm{C}$.

As observed for the Christophers' stages, an inverse relationship between temperature and time development was also observed when Sella stages were scored, and the process was not synchronous with oocyte maturation. Individuals were observed at different stages of oocyte development one day after the ingestion of blood at 24,27 , and $30^{\circ} \mathrm{C}$. However at 30 and $27^{\circ} \mathrm{C}$, the first individuals in the final stage of oocyte development (stage $\mathrm{G}$, gravid) were recorded at $24 \mathrm{~h}, 12 \mathrm{~h}$ earlier than at $24^{\circ} \mathrm{C}$.

Oocyte development times based on Sella stages differed significantly between the temperatures evaluated. The mean time required for oocyte maturation at $24^{\circ} \mathrm{C}$ was greater than at 27 or $30^{\circ} \mathrm{C}$. According to the mean development time, Sella's stage G was attained after 68.1 and $70.9 \mathrm{~h}$ at 27 and $30^{\circ} \mathrm{C}$ respectively, compared to 90.6 at $24^{\circ} \mathrm{C}$. This difference of one day in the appearance of the final developmental stage of An. albimanus oocytes was similar to that observed for Christophers' stage V.

Duration of the gonotrophic cycle - An inverse relationship was observed between temperature and dura- 


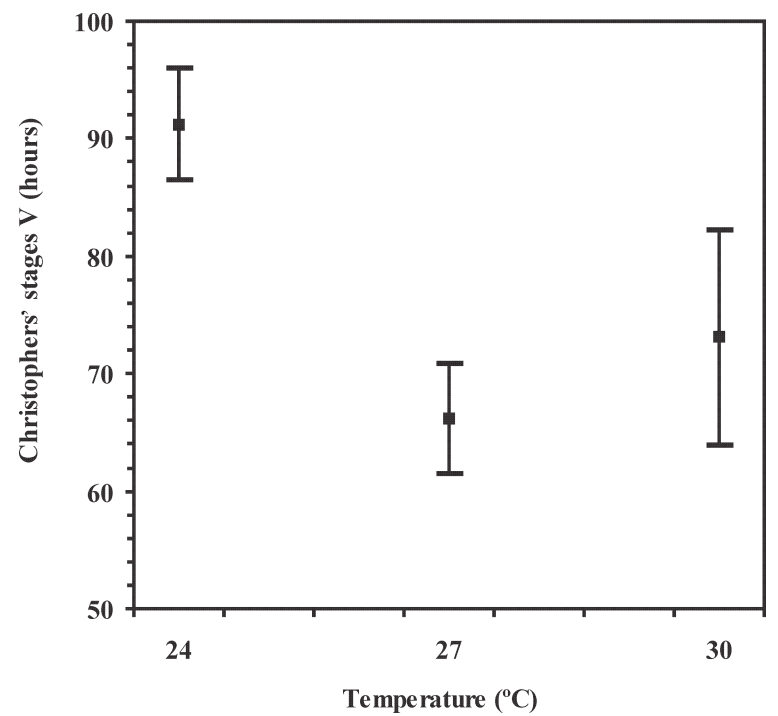

Fig. 1: mean duration and confidence intervals of oocyte development according to Christophers' stage $\mathrm{V}$ in Anopheles albimanus at 24,27 , and $30^{\circ} \mathrm{C}$.

tion of this cycle. The longest gonotrophic cycle of $A n$. albimanus was recorded at $24^{\circ} \mathrm{C}$, significantly different from those at 27 or $30^{\circ} \mathrm{C}$. No significant difference was observed between these last two temperatures (Fig. 2). A mean difference of $19.3 \mathrm{~h}$ was recorded between the gonotrophic cycles of An. albimanus at 24 and $30^{\circ} \mathrm{C}$. If one assumes that this same behaviour occurs in nature, this reduction in the duration of the gonotrophic cycle of the malaria vector An. albimanus could correspond to a reduction of approximately one day.

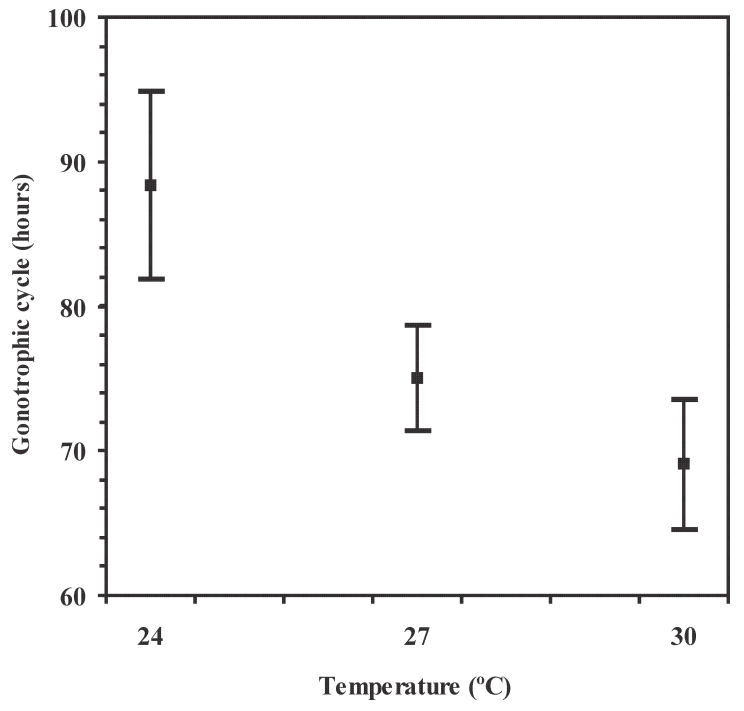

Fig. 2: mean duration and confidence intervals of the second gonotrophic cycle of Anopheles albimanus in relation to temperature variations under laboratory conditions.

Circadian rhythm of egglaying - More than $96 \%$ of the oviposition occurred at night, regardless the time of blood ingestion (Fig. 3). Only two mosquitoes laid eggs during the day (after dawn or near dusk). Likewise, the majority of mosquitoes laid their eggs at night-3 postfeeding, regardless the time of blood feeding. Similar to the oocyte maturation, oviposition showed asynchrony, taking place in several nights, starting on night- 2 , and up to night-5. At the three temperatures studied, the first oviposition took place in less time for the mosquitoes
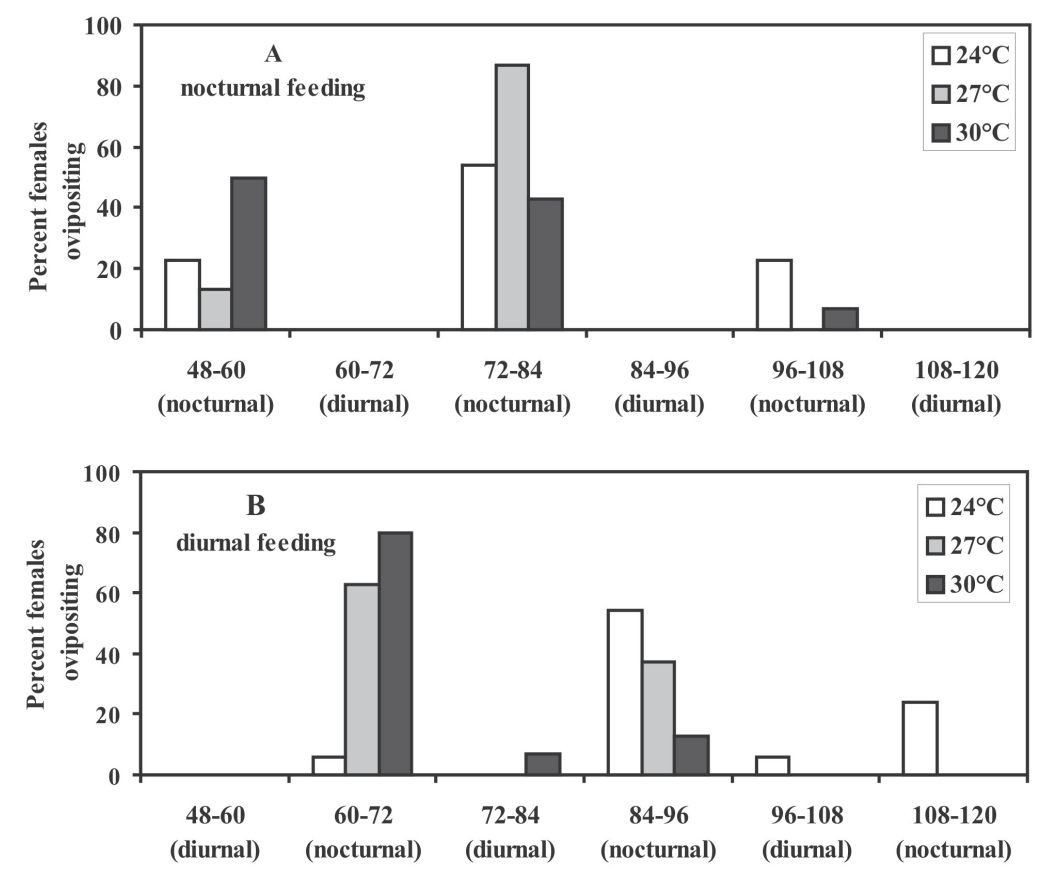

Ovipositing time

Fig. 3: percentage of Anopheles albimanus that laid eggs (day, night) according to the time of feeding (diurnal, nocturnal) at 24,27 , and $30^{\circ} \mathrm{C}$. 
that fed in the evening (48-60 $\mathrm{h}$ after blood feeding) while for mosquitoes that fed in the morning the first oviposition was observed at 60-72 $\mathrm{h}$ post-feeding.

\section{DISCUSSION}

The results of this study show the association between increments in the temperature and the reduction of the oocyte development time and the gonotrophic cycle in An. albimanus. The three temperatures evaluated corresponded to the range recorded in the malaria-endemic areas of Colombia under normal climatic conditions $\left(24^{\circ} \mathrm{C}\right)$ and also during El Niño periods $\left(27,30^{\circ} \mathrm{C}\right)$, which could help to explain the increase in malaria transmission during El Niño in Colombia.

The association between temperature and gonotrophic cycle was found to be nonlinear. With an increase in $3^{\circ} \mathrm{C}$, from 24 to $27^{\circ} \mathrm{C}$, a $13 \mathrm{~h}$ reduction in the gonotrophic cycle was observed, although no significant difference was recorded in cycle duration when shifting temperatures from 27 to $30^{\circ} \mathrm{C}$.

Reduction in oocyte development time and in duration of the gonotrophic cycle associated with increments in temperature has also been recorded for An. culicifacies, An. stephensi (Mahmood \& Reisen 1981), and An. maculipennis (Detinova 1962). Detinova (1962) expressed the relation between temperature and duration of the gonotrophic cycle of the vectors of malaria as a mathematical expression, based on the minimum temperature needed for development of the gonotrophic cycle and the thermal sum, which represents the number of degrees in the which the mean temperature of a day exceeds the lower threshold temperature of the gonotrophic cycle. Values of the thermal sum and the lower threshold temperature are unknown for malaria vectors in Colombia, which precludes calculation of the gonotrophic cycle length in response to changes in environmental temperature, such as those presented during El Niño events. Previous studies carried out on An. albimanus under laboratory conditions, have employed a relatively constant temperature to estimate the duration of the gonotrophic cycle. The mean duration of the cycle at $25^{\circ} \mathrm{C}$ has been reported as 4.5 days (Ramsey et al. 1988), while at $28^{\circ} \mathrm{C}$, the length of the oviposition cycle was four days, according to information used by Rubio-Palis (1994) to calculate the vectorial capacity of An. albimanus. These values differ from those obtained during this study, in which the duration of the gonotrophic cycle at 24,27 , and $30^{\circ} \mathrm{C}$ were $88.4 \mathrm{~h}(3.7$ days), $75 \mathrm{~h}$ (3.1 days), and $69.1 \mathrm{~h}$ (2.8 days) respectively.

In this study it was observed that not all the individuals laid eggs simultaneously. Similar observations were made by Chadee et al. (1993) indicating that, under laboratory conditions $\left(26 \pm 2^{\circ} \mathrm{C}\right)$, An. albimanus presents a bimodal rhythm of oviposition, egg laying being crepuscular (18:00-20:00) and nocturnal (4:00-6:00).

According to Haddow and Ssenkubuge (1962), anophelines generally oviposit during the night, as was observed for An. albimanus in the present study. A similar nocturnal pattern of oviposition has been reported for other species of Anopheles (Chadee 1995, 1999, Chadee et al. 1998). The oviposition process of An. albimanus appears to be under the control of an exogenous circa- dian rhythm caused by the day-night transition, as observed by Chadee et al. (1993) and also reported for other malaria vectors (Reisen \& Mahmood 1979). Consequently, despite the fact that the duration of egg development is reduced by effect of temperature, an external stimulus (such as the change from light to darkness) is probably required for oviposition to occur. If a similar type of behaviour occurs in nature, the reduction of a few hours in the duration of the egg development of An. albimanus would not have important effect on the oviposition period, since it would be the stimulus of the light-darkness change that would determine the timing of oviposition and thus the total duration of the gonotrophic cycle. However, a reduction in the duration of the gonotrophic cycle of about one day would have an important effect on the frequency of human-vector contact. In terms of malaria transmission, a reduction in the duration of the gonotrophic cycle could increase transmission of the disease, by increasing the frequency of human-vector contact.

Temperature has been observed to influence the embryonic development of some Anopheles species (de Carvalho et al. 2002). However, the oocyte maturation process in An. albimanus was variable, even when the mosquitoes were reared at the same temperature. Ovarian development along with blood requirement for oocyte maturation have been poorly studied in Neotropical anophelines. The present study found that after four days of feeding, some oocytes were still in early stages of development. This finding contrasts with those of $\mathrm{Lu}$ and Hagedorn (1986) who observed that at $27.5^{\circ} \mathrm{C}, \mathrm{An}$. albimanus eggs reached the most advanced stage of development $36 \mathrm{~h}$ after feeding.

Variations in environmental air temperature are witnessed during climatic events such as El Niño, or at longer timescales as a consequence of global warming (Wigley \& Raper 1992, IPCC 1996). These changes in air temperature affect the duration of the gonotrophic cycle of malaria vectors, as observed in this study. Although other variables such as source of blood meals (Ramsey et al. 1988), availability of hosts (Lindsay \& Birley 1996), number of previous cycles (Briegel \& Hörler 1993), retention of eggs (Chadee et al. 1993) or variability in the development time of the eggs may affect the gonotrophic cycle, its duration is fundamentally dependent on changes in temperature (Detinova 1962, Mahmood \& Reisen 1981, Lindsay \& Birley 1996, Martens 1997).

Field observations should be carried out during El Niño events to obtain evidence of changes in the duration of the gonotrophic cycle in natural populations. If increased microhabitat temperatures accelerate bloodmeal digestion and egg development, reducing the length of the gonotrophic cycle, the interval between blood meals would also be reduced. A shortening in this interval by one day as a result of increased temperature during El Niño would affect the dynamic of human-vector contact.

In terms of malaria transmission, a reduction in the duration of the gonotrophic cycle could increase transmission of the disease, by increasing the frequency of human-vector contact. However, in the dynamics of malaria transmission other variables, besides gonotrophic cycle, are sensitive to temperature changes, such as the 
duration of the sporogonic period (Macdonald 1957) and longevity (Garrett-Jones \& Grab 1964). During the El Niño event, since the average environmental temperature increases, the duration of the gonotrophic cycle and the sporogonic period may be shortened, as well as the vector longevity. As longevity is negatively affected by increase in temperature, and being this variable an important parameter in vectorial capacity, the effect of the reduction in the gonotrophic and sporogonic cycles, could counteract the effect of reduction in longevity. Efforts are being done in our group to have data for each variable for An. albimanus and use models to represent these interactions.

\section{ACKNOWLEDGEMENTS}

GP thanks CIRES (University of Colorado, Boulder, CO, US) for their support as a Visiting Fellow. To Dr Adeline Chan for reading and commenting on the manuscript and to David Alonso Calle for technical assistance in this study.

\section{REFERENCES}

Bouma MJ, Poveda G, Rojas W, Chavasse D, Quiñones ML, Cox J, Patz J 1997. Predicting high-risk years for malaria in Colombia using parameters of El Niño Southern Oscillation. Trop Med Int Health 2: 1122-1127.

Bown DN, Rodriguez MH, Arredondo-Jimenez JJ, Loyola EG, Rodríguez MC 1991. Age structure and abundance levels in the entomological evaluation of an insecticide used in the control of Anopheles albimanus in Southern Mexico. J Am Mosq Control Assoc 7: 180-187.

Briegel H, Hörler E 1993. Multiple blood meals as a reproductive strategy in Anopheles. J Med Entomol 30: 975-985.

Bruce-Chwatt LJ 1980. Epidemiology of malaria. In Essential Malariology, William Heinemann Medical Books Ltd, London, p. 129-168.

Carrillo MP, Suárez MF, Morales A, Espinal C 1981. Colonización y mantenimiento de una cepa Colombina de Anopheles albimanus Wiedemann, 1820 (Diptera: Culicidae). Biomédica 1: 64-66.

Chadee DD 1995. Diel oviposition patterns of Anopheles albitarsis in Trinidad, West Indies. J Am Mosq Control Assoc 11: 103-108.

Chadee DD 1999. Laboratory studies of diel oviposition, fecundity survival and gonotrophic cycle of Anopheles bellator Dyar and Knab in Trinidad, West Indies. $J$ Vector Ecol 24: 83-90

Chadee DD, Beier JC, Mohammed RT 1998. Laboratory studies of diel oviposition, fecundity survival and gonotrophic cycle in Anopheles homunculus. J Am Mosq Control Assoc 14: 153-158.

Chadee DD, Mendis C, Beier JC 1993. Diel oviposition mosquitoes (Diptera: Culicidae) from the Americas: Anopheles albimanus Wiedemann and Anopheles freeborni Aitken. Ann Trop Med Parasitol 87: 501-507.

Christophers SR 1911. The development of the egg follicle in anophelines. Paludism 2: 73-89.

de Carvalho SC, Martins Junior A de J, Lima JB, Valle D 2002. Temperature influence on embryonic development of Anopheles albitarsis and Anopheles aquasalis. Mem Inst Oswaldo Cruz, 97: 1117-1120.
Detinova TS 1962. Age grouping methods in Diptera of medical importance with special reference to some vectors of malaria. Monograph series 47, World Health Organization, Geneva.

Diaz HF, Markgraf V 2000. El Niño and the Southern Oscillation. Multiscale Variability and Global and Regional Impacts, Cambridge University Press, Cambridge, 496 pp.

Garrett-Jones C, Grab B 1964. The assessment of insecticidal impact on the malaria mosquito's vectorial capacity, from data on the proportion of parous females. Bull WHO 31 : 71-86.

Haddow AJ, Ssenkubuge Y 1962. Laboratory observations on the oviposition cycle in the mosquito Anopheles (Cellia) gambiae Giles. Ann Trop Med Parasitol 56: 352-355.

IPCC-Intergovernmental Panel on Climate Change 1996. Observed climate variability and change. Climate change 1995: the science of climate change. Contribution of working Group I to the second assessment report of the Intergovernmental Panel on Climate Change, Houghton JJ, Meiro Filho LG, Callender BA, Harris N, Kattenberg A, Maskell K, Cambridge University Press, p. 370-374.

Lindsay SW, Birley MH 1996. Climate change and malaria transmission. Ann Trop Med Parasitol 90: 573-588.

Lu YH, Hagedorn HH 1986. Egg development in the mosquito Anopheles albimanus. Internl Invertebrate Reproduction and Development 9: 79-94.

Macdonald G 1957. The Epidemiology and Control of Malaria, Oxford University Press, London, 201 pp.

Mahmood F, Reisen W 1981. Duration of the gonotrophic cycle of Anopheles culicifacies Giles and Anopheles stephensi Liston, with relation to observations on reproductive activity and survivorship during winter in Punjab Province, $\mathrm{Pa}-$ kistan. Mosq News 41: 41-50.

Martens P 1997. Health Impacts of Climate Change and Ozone depletion. An Eco-epidemiological Modelling Approach, $157 \mathrm{pp}$.

Martens P, Kovats RS, Nijhof S, De Vries P, Livermore MTJ, Bradley DJ, Cox J, McMichael AJ 1999. Climate change and future populations at risk of malaria. Glob Environ Change 9: S89-S107.

Molineaux L 1988. The epidemiology of human malaria as an explanation of its distribution, including some implications for its control. In WH Wernsdorfer, SI McGregor (eds), Malaria, Principles and Practice of Malariology, Churchill Livingstone, London, p. 913-998.

PAHO-Pan American Health Organization 1996. Biology and ecology of Anopheles albimanus Wiedemann in Central America, Technical paper 43, Washington, 44 pp.

Poveda G, Rojas W 1997. Evidencias de la asociación entre brotes epidémicos de malaria en Colombia y el fenómeno El Niño-Oscilación del Sur (ENSO). Rev Acad Colombiana de Ciencias Exactas, Físicas y Naturales 21: 421-429.

Poveda G, Graham NE, Epstein PR, Rojas W, Quiñones ML, Velez ID, Martens WJM 2000. Climate and ENSO variability associated with vector-borne diseases in Colombia. In HF Diaz, V Markgraf (eds), El Niño and the Southern Oscillation, Multiscale Variability and Global and Regional Impacts, Cambridge University Press, Cambridge, p. 183204. 
Poveda G, Rojas W, Velez ID, Quiñones ML, Mantilla RI, Ruiz D, Zuluaga J, Rúa GL 2001. Coupling between annual and ENSO timescales in the malaria-climate association in Colombia. Environ Health Perspect 109: 489-493.

Quiñones ML, Suárez MF, Fleming GA 1987. Distribución y bionomía de los anofelinos de la Costa Pacífica de Colombia. Colomb Med 18: 19-24.

Ramsey JM, Salinas E, Lopez JR, Del Angel-Cabanas G, Martinez L, Bown DN 1988. Laboratory oviposition, fecundity and egg hatching ability of colonized Anopheles albimanus from Southwestern Mexico. J Am Mosq Control Assoc 4: 509-515.

Reisen WK, Mahmood F 1979. Anopheles culicifacies Giles: some relationships among oviposition, refeeding and survivorship. Mosq News 39: 374-381.

Rodríguez MH, Bown DN, Arredondo-Jimenez JI, Villareal C, Loyola EG, Frederikson CE 1992. Gonotrophic cycle and survivorship of Anopheles albimanus (Diptera: Culicidae) in Southern Mexico. J Med Entomol 29: 395-399.

Rúa GL, Quiñones ML, Zuluaga J, Rojas W, Poveda G, Velez ID, Ruiz D, Mantilla R 2003. El Niño Southern Oscillation (ENSO) related to malaria transmission, density and parity of Anopheles albimanus (Diptera. Culicidae) in Colombia. In JL Aron, CF Corvalán, H Philippeaux (eds), Climate Variability and Change and their Health Effects in the Caribbean: Information for Adaptation Planning in the Health Sector, World Health Organization, Geneva, p. 24.

Rubio-Palis J 1994. Variation of the vectorial capacity of some anophelines in Western Venezuela. Am J Trop Med Hyg 50: 420-424.

WHO-World Health Organization 1975. Manual on Practical Entomology in Malaria. Part II: Methods and Techniques, Geneva, 191 pp.

Wigley TM, Raper SC 1992. Implications for climate and sea level of revised IPCC emissions scenarios. Nature 357: 293300 . 